\title{
Regulation of potato tuber sprouting
}

\author{
Sophia Sonnewald $\cdot$ Uwe Sonnewald
}

Received: 25 July 2013 / Accepted: 25 September 2013 / Published online: 8 October 2013

(C) Springer-Verlag Berlin Heidelberg 2013

\begin{abstract}
Following tuber induction, potato tubers undergo a period of dormancy during which visible bud growth is inhibited. The length of the dormancy period is under environmental, physiological and hormonal control. Sucrose availability is one prerequisite for bud break. In the absence of sucrose, no bud break occurs. Thus, sucrose is likely to serve as nutrient and signal molecule at the same time. The mode of sucrose sensing is only vaguely understood, but most likely involves trehalose-6-phosphate and SnRK1 signalling networks. This conclusion is supported by the observation that ectopically manipulation of trehalose-6-phosphate levels influences the length of the dormancy period. Once physiological competence is achieved, sprouting is controlled by the level of phytohormones. Two phytohormones, ABA and ethylene, are supposed to suppress tuber sprouting; however, the exact role of ethylene remains to be elucidated. Cytokinins and gibberellins are required for bud break and sprout growth, respectively. The fifth classical phytohormone, auxin, seems to play a role in vascular development. During the dormancy period, buds are symplastically isolated, which changes during bud break. In parallel to the establishment of symplastic connectivity, vascular tissue develops below the growing bud most likely to support the outgrowing sprout with assimilates mobilised in parenchyma cells. Sprouting leads to major quality losses of stored potato tubers. Therefore, control of tuber sprouting is a major objective in potato breeding. Although comparative transcriptome analysis revealed a large number of genes differentially expressed in growing versus dormant buds, no master-regulator of potato tuber sprouting has been identified so far.
\end{abstract}

S. Sonnewald $(\bowtie) \cdot$ U. Sonnewald

Lehrstuhl für Biochemie, Friedrich-Alexander Universität Erlangen-Nürnberg, Staudtstrasse 5, 91058 Erlangen, Germany

e-mail: sophia.sonnewald@fau.de
Keywords Potato tuber sprouting $\cdot$ Dormancy $\cdot$ Meristem activation · Plant hormone

$\begin{array}{ll}\text { Abbreviations } \\ \text { ABA } & \text { Abscisic acid } \\ \text { CK } & \text { Cytokinin } \\ \text { GA } & \text { Gibberellin } \\ \text { IAA } & \text { Indole-3 acetic acid } \\ \text { PPi } & \text { Inorganic pyrophosphate } \\ \text { SL } & \text { Strigolactones } \\ \text { SnRK } & \text { SNF1-related kinase } \\ \text { T6P } & \text { Trehalose-6-phosphate }\end{array}$

\section{Introduction}

Potato (Solanum tuberosum L.) is one of the most important crop plants worldwide. Potato tubers are an excellent staple food due to its high nutritional value. This in addition to their relatively easy cultivation makes potato more and more important as a critical crop to feed an increasing world population. Tubers are mainly consumed fresh, generating a constant all year round demand and making long-term storage of tubers after harvest necessary. The maintenance of post-harvest quality is of vital importance to producers and processors. Sprouting is one factor contributing to the quality loss leading to remobilisation of storage compounds, mainly starch and proteins and shrinkage due to loss of water (Coleman 1987; Sonnewald 2001; Börnke et al. 2007). The understanding of the molecular mechanisms and the development of diagnostic tools to predict sprouting are therefore of primary interest to ensure post-harvest tuber quality.

Potato tubers are stem-derived organs formed by shortened internodes and nodes which turn into tuber eyes. 
Tubers originate from underground shoots, called stolons, by swelling of the stolon tips. This process requires the cessation of diageotropical growth and a change from transverse to longitudinal cell division in pith and cortex (Xu et al. 1998). The bulk of tuber tissue is subsequently formed by cell expansion, randomly oriented cell division (Jackson 1999) and massive deposition of C- and N-assimilates such as starch and storage proteins (Visser et al. 1994; Appeldoorn et al. 1999), making the tuber a strong storage sink (Fernie and Willmitzer 2001). Tuber development is regulated by an interplay between endogenous and environmental signals and is orchestrated by coordinated transcriptional and metabolic changes (Kloosterman et al. 2005, 2008; Ferreira et al. 2010). The process was shown to be controlled by phytohormones including gibberellins (GAs), auxin and strigolactones (SLs) (Carrera et al. 2000; Kloosterman et al. 2007; Roumeliotis et al. 2012; Pasare et al. 2013). However, an important trigger comes from environmental cues. In many potato species, short photoperiods favour tuber initiation, while high temperatures (especially during the night) and high nitrogen levels are inhibitory (Jackson 1999; Abelenda et al. 2011). Under favourable conditions, a mobile tuberisation signal is produced in the leaves and is then transported to the stolons, inducing tuber formation. The nature of the signal has been identified as the potato homologue of the Flowering Locus T (FT), named as StSP6A (Navarro et al. 2011). The regulatory network of tuber induction is now emerging involving additional players which have been described recently (Hannapel 2010; Abelenda et al. 2011; Gonzalez-Schain et al. 2012; Kloosterman et al. 2013).

Coincident with tuber development, meristematic activity in the stolon apex and the nodes ceases completely and the tuber enters a period of dormancy (Burton 1989; $\mathrm{Xu}$ et al. 1998; Claassens and Vreugdenhil 2000). Thus, inception of dormancy largely parallels tuber enlargement (Fernie and Willmitzer 2001). Dormancy has been defined in broad terms as 'the absence of visible growth of any plant structure containing a meristem' (Lang et al. 1987) and is a physiological adaptation to survive periods of unfavourable environmental conditions. In potato tubers, dormancy occurs only in the tuber buds containing the meristem, the rest of the tuber remains metabolically active (Viola et al. 2007). Potato tubers pass through three phases of dormancy (Suttle 2007). The post-harvest dormancy phase is defined as endodormancy in which growth arrest is caused by endogenous factors and cannot be broken even under otherwise favourable conditions. After a certain time, endodormancy is lost, and tubers are physiologically competent to sprout (Sonnewald 2001). Usually the apical bud becomes dominant and inhibits the outgrowth of other buds which are paradormant. Moreover, sprouting can be inhibited by limiting environmental conditions, e.g. cold which is referred to as ecodormancy (Suttle 2007). The stem-like behaviour of tubers was confirmed in a recent study (TeperBamnolker et al. 2012). In addition, the weakening of the apical dominance leading to sprouting of multiple buds during the later stages of development was linked to programmed cell death in this study.

With the onset of sprouting, tubers become a source organ for the growing sprout (Sonnewald 2001). This is accompanied by structural and metabolic changes as well as by an altered level of gene expression (Ronning et al. 2003; Viola et al. 2007; Hartmann et al. 2011). Although our knowledge with respect to molecular changes during tuber dormancy has considerably increased within the last years, the molecular mechanisms triggering tuber sprouting are still unclear. Changes in the meristematic activity are thought to play a key role in sprouting and re-activation of meristem function is assumed to coincide with the end of dormancy. Here, we will summarise the current knowledge of molecular and metabolic processes controlling length of dormancy and onset of sprouting.

\section{Environmental conditions affecting length of tuber} dormancy

Besides being under genetic control, length of tuber dormancy is influenced by both pre- and post-harvest environmental factors. Since tuber dormancy is established during tuber formation, it is not surprising that factors influencing tuberisation such as day length, temperature, nutrient and water supply also affect dormancy and sprouting (summarised in Jackson 1999; Claassens and Vreugdenhil 2000; Suttle 2007). Early work reported that potatoes cultivated under short days have a shorter dormancy period than those grown under long-day conditions (Emilsson 1949; reviewed by Claassens and Vreugdenhil 2000). Besides day length, temperature has a strong impact on tuber development. High temperatures during the growing season not only have negative effects on tuber formation and tuber dry matter accumulation, but also cause tuber chain formation, secondary growth and premature sprouting (Bodlaender et al. 1964; Levy and Veilleux 2007). Heat stress during tuber maturation is thought to interfere with the onset of dormancy; the stolon tips resume growth and can form a second tuber under favourable conditions, e.g. if temperature becomes cooler again. Repeated cycles of high and low nitrogen level can also result in the formation of chain tubers (Jackson 1999).

Temperature is also one of the most important physical factors determining the length of dormancy period during storage: within the range of $3-20{ }^{\circ} \mathrm{C}$, dormancy length is inversely proportional to temperature (Wiltshire and Cobb 1996). Other post-harvest conditions such as humidity and the composition of the atmosphere also impair dormancy 
(see Wiltshire and Cobb 1996; Claassens and Vreugdenhil 2000; Suttle 2007).

In addition, sprout control is achieved commercially by application of chemical or natural compounds (Sonnewald 2001). The synthetic chlorpropham (isopropyl $N$-chlorophenylcarbamate, CIPC) is the most effective sprout inhibitor which prevents tuber sprouting by interfering with its cell division (Vaughn and Lehnen 1991; Campbell et al. 2010). However, its application raises environmental and consumer concerns. Natural compounds like mint essential oil or caraway and their volatiles have been described as environmentally friendly alternatives to inhibit sprouting (Meigh 1969; Eshel et al. 2009; Teper-Bamnolker et al. 2010). The mode of action of these compounds is under investigation and interested readers are referred to Eshel et al. (2009); Teper-Bamnolker et al. (2010) and Rentzsch et al. (2012) (and ref. therein). Besides inhibition, sprouting can be chemically induced by application of "Rindite" or bromoethane (BE) (Coleman 1983). Both are rapid inducer of dormancy break. BE-induced sprouting was shown to result in similar morphological, physiological and transcriptional changes as natural cessation of dormancy and has been established as one experimental model system to synchronously release tuber dormancy (Law and Suttle 2003, 2004; Destefano-Beltran et al. 2006a; Campbell et al. 2008; Alexopoulos et al. 2009).

\section{Changes in plant primary metabolism}

During tuber development, imported soluble assimilates are actively converted into starch and storage proteins. At maturity, between 8.0 and $29.4 \%$ of dry matter is made of starch, and between 0.69 and $4.63 \%$ of storage proteins (OECD 2002). Using $\left[\mathrm{U}_{-}{ }^{14} \mathrm{C}\right]$ glucose labelling, Viola et al. (2007) showed that the starch-synthesising capacity of parenchyma cells declines during maturation, while there is an increased partitioning of labelled glucose into sucrose suggesting that tubers undergo a sink-to-source transition. After the onset of sprouting, the soluble sugar content in the tubers declined until sprouts reached approximately $1 \mathrm{~g}$ of dry matter (Viola et al. 2007). Remarkably, induction of starch mobilisation in parenchyma cells was only found during the late stages of sprouting, which correlated with an accumulation of soluble sugars (Viola et al. 2007). These data are consistent with other reports in which decreased sucrose and unchanged starch levels were found in parenchyma cells during storage and the onset of sprouting (Davies and Ross 1984, 1987; Biemelt et al. 2000; Hajirezaei et al. 2003). Activities and transcript abundance of alpha- and beta-amylases were found to increase in the sub-eye regions of tubers with the commencement of sprouting, but not in the tuber parenchyma (Biemelt et al. 2000; Rentzsch et al. 2012), reflecting the increase in starch

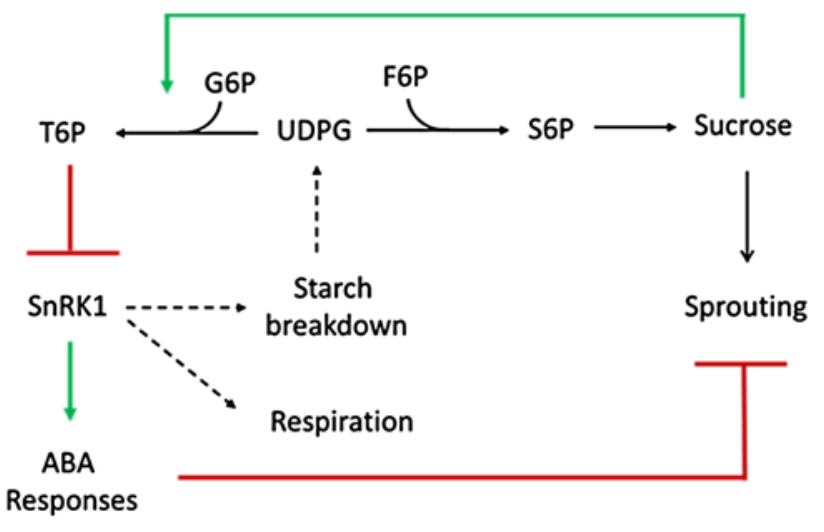

Fig. 1 Model of metabolic regulation of potato tuber sprouting. Sucrose transport into the tuber buds is a prerequisite to induce tuber sprouting. In parenchyma cells, sucrose levels decline during the dormancy period. Sucrose content correlates with the level of the signal metabolite trehalose-6-phosphate (T6P) which is supposed to decline with dormancy progression. Considering data of Debast et al. (2011), a low T6P content may stimulate an increased reserve mobilisation and respiration by activation of the SnRK signalling pathway (dotted lines). Increased mobilisation of reserves such as starch during advanced stages of sprouting will fuel the energy demand of the growing sprout. Furthermore, activation of SnRK1 signalling has been linked with an activation of ABA catabolism. Low ABA levels are necessary for dormancy progression and sprout induction. Green arrows indicate positive control; red arrows illustrate a negative regulation

turnover in the meristematic tissue and that starch degradation is important to maintain sprout growth.

Initial bud outgrowth does not require massive reserve mobilisation but is fed by sucrose-synthesising capacity that ensures rapid conversion of hexoses into sucrose that can be transported into growing buds to meet its energy demand. This was concluded from labelling experiments which revealed similar metabolic competence, but different metabolite pools in dormant and open tuber buds with respect to sugar metabolism (Viola et al. 2007). While resting buds contained only limited amounts of soluble sugars, there was a massive increase especially in the amount of sucrose at bud break indicating that sucrose unloading into the buds is a prerequisite for bud outgrowth (see Fig. 1).

Considering this, sucrose mobilisation and transport have been exploited as target to modify sprouting behaviour. Phloem cell-specific expression of a yeast-derived invertase which cleaves sucrose into glucose and fructose caused a strong inhibition of tuber sprouting (Hajirezaei et al. 2003). While tubers of untransformed control plants developed sprouts after 5 months of storage, transgenic tubers only formed diminutive sprouts which did not exceed a 1-2 mm stage, even after prolonged storage. Interestingly, in these transgenic tubers, starch degradation and respiration were found to be accelerated together with an increased pool of phosphorylated hexoses and glycolytic intermediates. From 
these results, it was proposed that low sucrose levels in the bud (sink) may act as signal to regulate starch mobilisation in the parenchyma (source) (Hajirezaei et al. 2003). This hypothesis was substantiated by transgenic plants expressing a chimeric sucrose isomerase which catalyses the conversion of sucrose into the non-metabolizable palatinose without affecting the hexose metabolism. Tubers of these transgenic plants were characterised by low sucrose levels and showed an increased starch degradation and respiration during storage (Hajirezaei et al. 2003). Since hexose levels were almost unchanged in these plants, it was concluded that the absence of sucrose in meristematic cells may serve as a signal to initiate reserve mobilisation and respiration. In addition, these data indicated that phloem-restricted sucrose hydrolysis inhibits translocation of sucrose towards the developing sprouts leading to a non-sprouting phenotype (Hajirezaei et al. 2003).

Since sucrose utilisation via sucrose synthase and UDPglucose pyrophosphorylase is dependent on inorganic pyrophosphate (PPi) (Sonnewald 2001), removal of PPi was used as another approach to interfere with sucrose availability by overexpression of an Escherichia coli pyrophosphatase. Expression of this gene under control of a strong constitutive promoter resulted in a strong delay of tuber sprouting which was thought to be brought about by a reduced phloem loading of sucrose and the impaired utilisation of sucrose in the developing sprout (Hajirezaei and Sonnewald 1999). Sink tuber-specific expression of E. coli pyrophosphatase caused the opposite phenotype, namely accelerated sprouting (Farre et al. 2001). In this case, removal of PPi in parenchyma cells resulted in higher sucrose levels which could be loaded into the phloem system causing higher sucrose levels in meristematic cells (Farre et al. 2001; Sonnewald 2001).

In a recent study, trehalose-6-phosphate (T6P) was shown to affect tuber dormancy (Fig. 1). T6P has emerged as a component of plant's sugar signalling system (Paul 2007; Debast et al. 2011) and its amount was shown to correlate with sucrose content under natural conditions (Lunn et al. 2006). Artificial manipulation of T6P content in transgenic plants by overexpression of bacterial enzymes had significant effects on tuber dormancy (Debast et al. 2011). Decreased levels of T6P resulted in early tuber sprouting, while increased levels of T6P lead to late sprouting. Assuming that T6P serves as signal metabolite to transmit the actual availability of sucrose, this observation is not consistent with the results obtained. However, assuming that ectopic expression of T6P metabolising enzymes uncouples in vivo sucrose content from T6P levels, the observed phenotypes may be explainable. High T6P levels in heterotrophic tissues will inhibit SnRK1 activity. Thus, reserve mobilisation and energy metabolism will be inhibited. As a consequence, less sucrose will be formed and sprout growth will not be supported. Two lines of evidences support this assumption. Firstly, tubers of transgenic plants expressing SnRK1 antisense transcripts also showed delayed tuber sprouting (Halford et al. 2003). Secondly, low T6P levels in potato tubers resulted in the up-regulation of a number of genes which have been shown to be SnRK1-responsive in arabidopsis leaves (Baena-Gonzalez 2010). Thus, it is tempting to speculate that reduced T6P levels caused an increased reserve mobilisation via SnRK1 signalling, increased sucrose levels and accelerated sprouting, while elevated T6P levels caused the opposite effect (see Fig. 1). From these data, it can be speculated that the reason for the observed sprouting phenotypes is the misinterpretation of the metabolic status of the tuber tissue.

Moreover, Debast et al. (2011) demonstrated an altered gibberellin (GA) and cytokinin (CK) response of the transgenic tubers with modified T6P levels and a changed turnover of abscisic acid (ABA), which correlated with the sprouting phenotype. The potential interaction between SnRK1 and ABA signalling is supported by the induction of ABA 8'-hydroxylase expression, which was found in low T6P tubers together with a reduced ABA content. This led the authors to suggest that induction of ABA catabolism through SnRK1 signalling may cause premature sprouting (Debast et al. 2011) (Fig. 1).

\section{Structural changes}

In agreement with the observation that sucrose supply of the meristem is important to meet the energy demand of the developing sprout, Viola et al. (2007) demonstrated that the symplastic connectivity of the meristem is restored with the onset of sprout growth. They observed no unloading of the carboxyfluorescein (CF) into the apical meristem during initiation of dormancy, indicating that the apical meristem is disconnected from the surrounding parenchyma cells at this developmental stage. With the onset of bud outgrowth, a strong phloem transport of $\mathrm{CF}$ into the growing buds and an extensive unloading of the dye into the meristem cells were detected. Hence, the symplastic isolation of the meristem is abolished with bud break, facilitating the translocation of sucrose into the meristematic cells (Viola et al. 2007). These results could be confirmed in transgenic potato tubers expressing GFP under the control of the phloem cell-specific sucrose transporter (Suc2) promoter of Arabidopsis. The Suc2::GFP has been established as a marker for sink-source transitions (Imlau et al. 1999; Oparka et al. 1999). In transgenic Suc2::GFP expressing potato plants, we noticed that the symplastic isolation observed in dormant tuber buds is released with bud break (Fig. 2). Collectively, these data led to assume that phloem connectivity changes during development and this allows transport of sucrose into the 

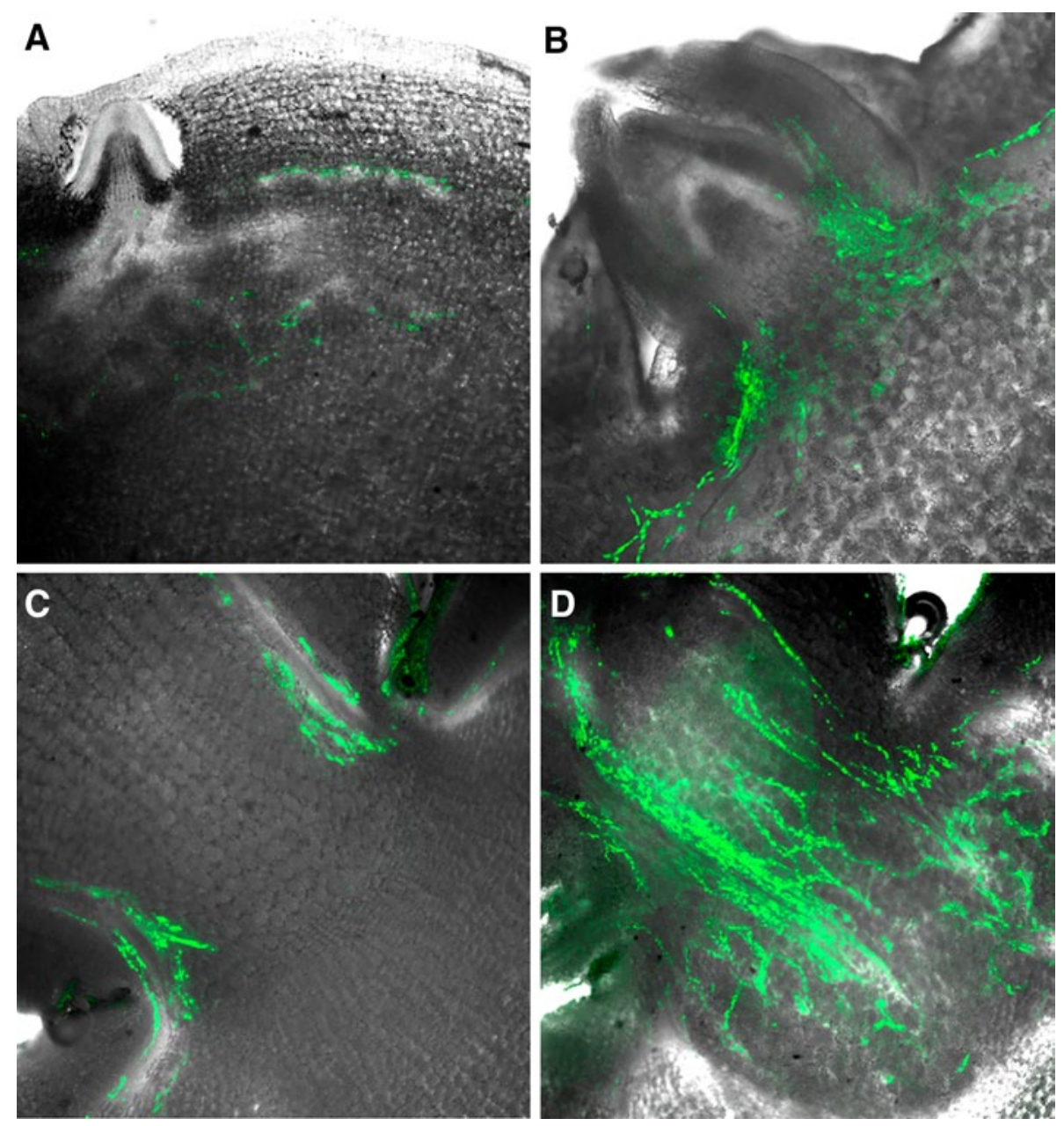

Fig. 2 The symplastic isolation of potato tuber buds is released with bud break. Potato plants were transformed with the Suc2::GFP reporter construct (Imlau et al. 1999). Suc2::GFP is expressed in companion cells of source tissue and GFP is shown to be phloem mobile and to traffic via plasmodesmata to sink tissues where it can be symplastically unloaded. Here, we used the construct as a marker for active unloading of assimilates (sucrose) into the meristematic cells of tuber buds. Cross sections through the apical bud area of tubers at different developmental status were inspected at a confocal

buds to supply assimilates for bud growth. However, the detailed structural changes are not clear so far and require further histochemical studies.

Symplastic isolation was shown in other species to result from callose deposition at plasmodesmata which join neighbouring cells to build a symplastic continuum (Oparka et al. 1999; Rinne et al. 2001). Furthermore, reestablishment of symplastic connections has been associated with callose removal by the action of beta-1,3-glucanases leading to the release of dormancy in perennial trees (Rinne et al. 2001, 2011). Whether modification of plasmodesmata through callose deposition and its removal are factors contributing to the regulation of potato tuber dormancy is presently unclear. scanning microscope. a Dormant tuber bud; no unloading of GFP can be seen into the apical bud or the region beneath. This is indicative for the symplastic isolation of the bud from the subtending tissue. $\mathbf{b}$, c Bud break; unloading of GFP into the bud is detectable, indicating the connection of the meristem cells in the bud and the surrounding parenchyma cells. d Sprouting bud; strong connection of the sprout and the parenchyma region below via vascular strands, indicating the massive transport of assimilates into the meristematic cells of the growing sprout

\section{Hormonal control}

Abscisic acid is required for both initiation and maintenance of tuber dormancy (Suttle and Hultstrand 1994). The significance of ABA as dormancy-related hormone was first recognised by Hemberg (1949). At this time, ABA was named beta-inhibitor complex. Consistently, subsequent studies showed that ABA levels are highest in deeply dormant tubers and decline during storage (Korableva et al. 1980; Biemelt et al. 2000; Destefano-Beltran et al. 2006b). In addition, treatment of microtubers with the ABA biosynthesis inhibitor fluridone reduced the ABA content significantly which was accompanied by a shortened dormancy period (Suttle and Hultstrand 1994). 


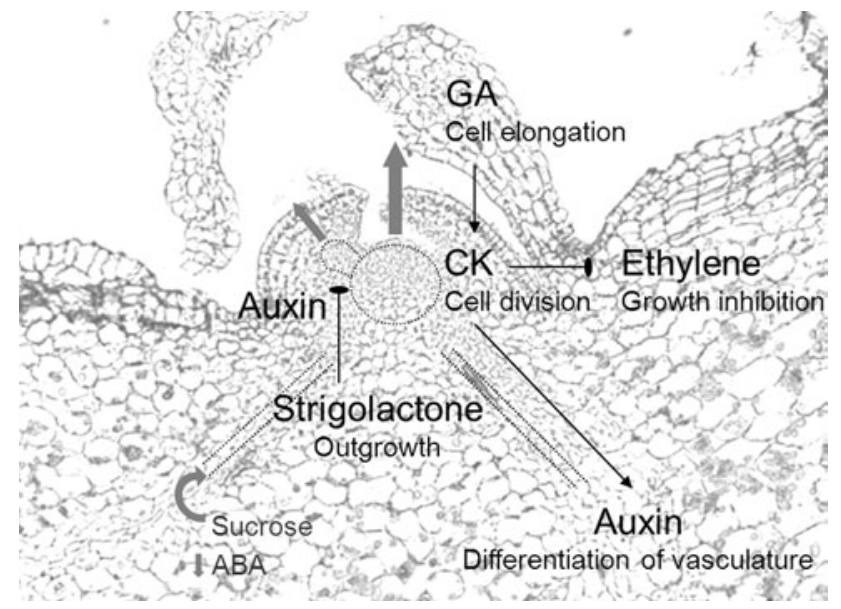

Fig. 3 Current model of hormonal regulation of tuber dormancy and sprouting. Sucrose transport into the parenchyma cells and low ABA levels are prerequisites for induction of tuber sprouting. Cytokinin $(\mathrm{CK})$ is supposed to be a central player, stimulating cell division in buds and coordinating auxin and ethylene pathways/responses. While auxin may be important for the (early) differentiation of the vasculature and apical bud growth, ethylene inhibits growth and hence is down-regulated during initiation of sprouting. Gibberellins (GA), long known as the dormancy breaking hormone, requires the presence of CK to favour shoot outgrowth and elongation. Lately, strigolactones (SL) were reported as negative regulator acting downstream of GA and CK. For more details, see text

However, exogenous application of ABA to dormant tubers had no remarkable effect, while treatment of nondormant tubers only transiently inhibited sprout growth (Suttle et al. 2012).

Quantitative RT-PCR (qPCR) analysis of ABA biosynthetic genes zeaxanthin epoxidase (ZEP) and 9-cisepoxycarotenoid dioxygenase (NCED) and of genes coding for the catabolic ABA 8'-hydroxylase revealed that tuber ABA content is the result of a balanced synthesis and degradation. The decline of ABA content with dormancy progression correlated with decreased expression of NCEDI/2 and higher expression of ABA 8'-hydroxylase (Destefano-Beltran et al. 2006b). Similarly, transgenic plants with modified T6P levels showed an altered dormancy period and an altered expression of ABA $8^{\prime}$-hydroxylase. The level of ABA 8'-hydroxylase expression inversely correlated to ABA levels and positively to bud break (Debast et al. 2011). In another study, ABA 8'-hydroxylase activity was inhibited by a range of chemical substances which resulted in elevated, endogenous ABA content. However, this treatment had no significant effect on dormancy duration (Suttle et al. 2012). Hence, although a decline in ABA content is associated with dormancy progression and appears to be a prerequisite for dormancy break (Fig. 3), there is most likely no particular threshold concentration below which dormancy is broken (Biemelt et al. 2000; Suttle 2004b; Suttle et al. 2012).
Besides ABA, ethylene also appears to play a critical role in the initiation of dormancy. However, whether there is an interaction with ABA signalling is unknown (Suttle 1998a). Conflicting data have been published concerning its role during later stages of dormancy and sprouting as summarised by Suttle (2004b, 2007). In brief, exogenous application could either shorten or delay the dormancy period depending on the duration of treatment and the concentration applied (Rylski et al. 1974; Prange et al. 1998). Previously, Suttle (2009) reported that neither ethylene application nor stimulation of endogenous biosynthesis was effective in bud break or sprout growth. In contrast, several publications described an increased rate of ethylene production and increased expression of biosynthetic genes with the onset of sprouting (Suttle 2004b, 2008, 2009; Hartmann et al. 2011, and ref. therein). Nonetheless, comparison of sprouting and non-sprouting tubers suggested that ethylene-associated signals may negatively influence sprout outgrowth (Hartmann et al. 2011) (see Fig. 3).

Thus, while ABA and ethylene have been mainly linked with the onset and maintenance of tuber dormancy, GAs and CKs have been associated with release of dormancy and sprouting. Since the mid-1950s, it has been known that application of GA triggers tuber sprouting (Brian et al. 1955; Rappaport 1956; Rappaport et al. 1957). The dormancy-releasing capacity of GA was confirmed more recently by either injecting GA below the apical bud complex or by bathing isolated tuber buds in $\mathrm{GA}_{3}$ solution (Suttle 2004b; Hartmann et al. 2011; Rentzsch et al. 2012). In all these studies, treatment with bioactive GA species was able to terminate dormancy and to stimulate bud outgrowth. First attempts to measure endogenous GA-like substances supported the idea that sprouting is related to an increase in GA level prior to or with the onset of sprouting (Smith and Rappaport 1961; Bialek and Bielinska-Czarnecka 1975). Improved detection methods, however, showed no significant changes, or even a decrease in the amount of $\mathrm{GA}_{1}$, which is the main bioactive GA in potato, and its direct precursors $\mathrm{GA}_{19}$ and $\mathrm{GA}_{20}$ during the dormancy period. A clear increase was only seen when sprouts started to grow vigorously (Suttle 2004a).

Transgenic lines with ectopic expression of the GA biosynthetic gene GA20-oxidase from either potato or Arabidopsis thaliana exhibited a shortened time of dormancy and developed elongated sprouts, confirming the growth promoting activity of GA (Carrera et al. 2000; Hartmann et al. 2011). In contrast, modified expression of endogenous GA2-oxidase gene, whose product is involved in inactivation of bioactive GAs and their precursors (Hedden 2001), did not affect the length of the dormancy period in transgenic potato tubers (Kloosterman et al. 2007). The onset of sprouting was delayed, however, in transgenic tubers expressing a heterologous GA2-oxidase from Arabidopsis 
(Hartmann et al. 2011) supporting the dormancy-terminating capacity of GA. The observed discrepancy might be due to different expression levels obtained in the different transgenic lines and the promoter used. In the study of Hartmann et al. (2011), the Arabidopsis GA20-oxidase was expressed under the control of either the constitutive CaMV35S or the chimeric STLS1/CaMV35S promoter. The chimeric promoter drives very strong expression during potato tuber storage as compared to the conventional CaMV35S promoter. Thus, it is tempting to speculate that the amount of bioactive GA must exceed a certain limit in responding cells to stimulate dormancy break and sprout outgrowth.

Strikingly, transgenic potato plants expressing the catabolic cytokinin oxidase/dehydrogenase 1 (CKX1) from $A$. thaliana to lower the $\mathrm{CK}$ content did not respond to $\mathrm{GA}_{3}$ application in an in vitro assay. Accordingly, transgenic tubers harbouring the isopentenyltransferase (IPT) gene from Agrobacterium tumefaciens to increase the endogenous CK content promoted GA-mediated sprouting in vitro (Hartmann et al. 2011). Furthermore, CKX1-expressing tubers exhibited a prolonged dormancy period and onset of sprouting was delayed up to 8 weeks compared to wild type (Hartmann et al. 2011). Even though bud break occurred in these tubers and petite sprouts were formed, they failed to develop further. These results support earlier findings that $\mathrm{CK}$ plays an essential role in the control of dormancy and sprouting (Hemberg 1970; Turnbull and Hanke 1985a; Suttle 2001, 2008). Suttle (2008) reported that synthetic phenylurea and nitroguanidine CKs were more effective in dormancy termination than the naturally occurring zeatin species because they escape inactivation by endogenous CKX. Moreover, these substances reduced the insensitivity against cytokinin that has been described during the early phases of dormancy (Turnbull and Hanke 1985b; Suttle 1998b), but did not eliminate it. Similarly, transgenic potato tubers which express a bacterial 1-desoxy-D-xylose-5-phosphate synthase showed increased level of trans-zeatin riboside and were characterised by broken dormancy at the time point of harvest, but further elongation of sprouts began only after a lag phase (Morris et al. 2006). The authors presumed hormonal and/or metabolic imbalances as reasons for this phenotype. This is in line with the assumption that metabolic competence has to be achieved (e.g. sucrose availability) for sprouting to commence (Sonnewald 2001). Nonetheless, applying 6-benzylaminopurine (BAP), another synthetic CK, to excised tuber buds in an in vitro sprout release assay stimulated bud break, but not sprout growth. An additional dosage of $\mathrm{GA}_{3}$ was necessary to trigger further sprouting (Hartmann et al. 2011). Together, these results place $C K$ as important player for bud break and initiation of tuber sprouting. Further they indicate the importance of metabolic and hormonal balance for this process and suggest that GA activity requires $\mathrm{CK}$ to stimulate meristematic activity and bud break. However, if applied exogenously GA is sufficient and necessary to promote sprout outgrowth (Fig. 3).

Although auxin is a key regulator of plant growth and development, its role during tuber dormancy and sprouting is not well understood and has been poorly investigated. Exogenous application of high concentrations of indole-3 acetic acid (IAA) or 1-naphthaleneacetic acid resulted in an inhibition of sprout growth, while application of low doses of auxin to bud containing tuber slices had a growth stimulating effect (Hemberg 1949, 1985; Suttle 2007). Inconsistent data have been also published concerning changes in endogenous levels of IAA. Bioassay and HPLC-derived data suggested an increase of IAA levels after bud break (Hemberg 1949; Sukhova et al. 1993), indicating no direct role for auxin in dormancy control. Later, Sorce et al. (2000) found a positive correlation between IAA content in tuber buds and loss of dormancy. In a more detailed analysis of different tuber tissues of two cultivars with different dormancy length stored at 3 or $23{ }^{\circ} \mathrm{C}$, Sorce et al. (2009) showed a progressive decline in levels of free and conjugated IAA in tuber buds until sprouting commenced. Parallel immunolocalisation experiments confirmed highest amounts of IAA in the buds with a different distribution in dormant and sprouting tubers. In dormant tubers, IAA was detectable in apical buds and lateral meristems as well as in developing vascular tissues underneath the meristems. However, IAA accumulated only in axillary primordia of sprouting buds (Sorce et al. 2009). From these results, the authors suggested that IAA may activate early differentiation processes, e.g. development of vasculature in the buds which is a prerequisite to terminate dormancy and initiate sprouting (Fig. 3). In fact, auxin was shown to play an essential role in primordium initiation and differentiation of vascular tissue (Carraro et al. 2006; Dettmer et al. 2009; Scarpella et al. 2010). In this context, the view of Sorce et al. (2009) is indirectly supported by transcript profiling data from tubers expressing the A. thaliana $C K X 1$ gene. Besides the strongly delayed sprouting phenotype, these tubers did not develop proper sprouts and showed anatomical disorders. Compared to wild type, genes coding for auxin biosynthesis, transport or signalling components were less induced or regulated in the opposite manner in CKX1-expressing tubers (Hartmann et al. 2011). Together, these results suggested that auxin biosynthesis, transport and signalling may be required for cellular differentiation (such as the vascular tissue) during bud break and outgrowth, but this needs more investigations.

In addition to auxins, strigolactones (SL) emerged as carotenoid-derived plant hormones with a major role in the control of lateral bud outgrowth (reviewed recently by Gong et al. 2012; Ruyter-Spira et al. 2013). Application 
of the synthetic SL GR24 to excised tuber buds alone had no significant effect on bud growth compared to water, whereas it inhibited the sprout inducing activity of GA and CK when applied together with these hormones (Pasare et al. 2013). Transgenic potato plants with RNAi-mediated silencing of the carotenoid cleavage dioxygenase 8 (CCD8), a key SL biosynthetic gene, revealed that SL are involved in the control of shoot branching and different processes during the tuber life cycle (Pasare et al. 2013). Tubers from these transgenic lines exhibited increased secondary growth and a reduced dormancy indicating a negative control of SL on sprouting. Remarkably, CCD8-RNAi tubers were less responsive to $\mathrm{GA}_{3}$ than wild-type tubers in an in vitro sprout release assay, but responded in a similar manner to CK treatment. The authors discuss this somehow unexpected result by an interaction between SL and GA which needs to be studied in more depth (Pasare et al. 2013). However, taken together, the results indicate that SL inhibited tuber bud growth and may act downstream of CK and GA (Fig. 3).

\section{Cellular and transcriptional changes}

Re-activation of meristematic activity precedes tuber bud growth and is accompanied by increased cell division leading to tuber sprouting. Campbell et al. (1996) showed that nuclei isolated from meristematic cells of dormant potato tubers are arrested in $G_{1} / G_{0}$ phase of the cell cycle and onset of visible sprouting coincided with increased ${ }^{3} \mathrm{H}$-thymidine incorporation into DNA indicating that cells reenter cell cycle at G1 phase. This is followed by DNA replication during S-phase. In fact, earlier studies have found that breaking of tuber dormancy is associated with an increase in net DNA and RNA synthesis (Macdonald and Osborne 1988). Recently, a deoxyuridine triphosphatase (dUTPase), which is important for continuous DNA replication, was described as molecular marker to define the switch from dormant to an active tuber meristem (Senning et al. 2010).

Further work revealed that epigenetic changes are involved in regulation of dormancy and linked these to an increased rate of cell division and re-activation of meristematic activity. Thus, an transient decrease in $5^{\prime}$-CCGG-3' methylation (Law and Suttle 2003) has been observed concurrently with an increased histone (H3.1, H3.2, H4) acetylation (Law and Suttle 2004) in meristems of cold-shifted or BE-treated (which triggers dormancy release) tubers prior to an accelerated RNA and DNA synthesis. Both cytosine demethylation of promoter regions and lysine acetylation of histone proteins are therefore thought to be part of the molecular events which activate transcription and gene expression during the transition from dormant to active tuber meristem cells.
Besides this, different approaches were performed to identify genes differentially expressed during the transition from dormant to sprouting tubers. Bachem et al. (2000) used cDNA-AFLP fingerprinting to identify transcriptderived cDNAs (TDFs) that are specifically expressed during the different stages of the tuber life cycle including the dormancy and sprouting phase. In total, they estimated that about 40,000 genes are expressed during tuber life cycle. The number of TDFs that change during development was found to be highest during tuber growth, lowest during dormancy and raised again during bud break and onset of sprouting. Seventy-five TDFs with changing expression during dormancy and sprouting were isolated and sequenced. However at this time, the majority of the sequences did not show any similarity to known genes, the others were similar to genes coding for homeotic proteins or transcription factors, but not for genes with homology to genes involved in catabolic carbohydrate metabolism (Bachem et al. 2000).

Other studies used large-scale sequencing technologies to generate expressed sequence tags (ESTs) from cDNA libraries specific for different potato tissues or developmental stages (Crookshanks et al. 2001; Ronning et al. 2003; Kloosterman et al. 2008) together with a comparative bioinformatics analysis to identify genes associated with dormancy and sprouting. Ronning et al. (2003) found genes involved in translation such as elongation factor EF1Balpha and ribosomal proteins among the highest differentially expressed genes during sprouting, consistent with an increased cellular activity.

Alternatively, differential display (Agrimonti et al. 2000) or suppression subtractive hybridisation (SSH) approaches using dormant and sprouting tubers (FaivreRampant et al. 2004; Liu et al. 2012) were applied to produce cDNA libraries enriched in genes up-regulated during dormancy release. Agrimonti et al. (2000) identified two genes, referred to as G1-1 and A2-1, whose expression was induced or strongly repressed during transition from dormancy to sprouting. Tubers of transgenic potato plants harbouring an antisense construct for G1-1 exhibited a significant increase in length of dormancy, while reduced expression of A2-1 had no effect on tuber dormancy (Marmiroli et al. 2000).

The SSH study conducted by Faivre-Rampant et al. (2004) yielded 385 differently regulated genes. Annotation and functional grouping indicated high proportion of genes involved in transcription and translation which reflect again the increased biosynthetic activity upon release of dormancy. Special attention was paid to a member of the auxin response factor family (ARF6). ARF6 gene expression was strongly up-regulated on release from dormancy. In situ hybridisation experiments revealed it is highly expressed in the meristem as well as in the procambial and early vascular 
tissue of sprouting buds, while no signal could be detected in dormant buds. As its transcript level correlated with meristem growth in several other conditions, the authors suggested ARF6 as a marker for meristem activation (FaivreRampant et al. 2004). A more recently performed SSH strategy led to the identification of approx. 300 differentially expressed ESTs and the authors described an ADP-ribosylation factor to be co-regulated with tuber dormancy break; however, they did not compare their data with the previously published results (Liu et al. 2012).

The construction of potato EST libraries and the increasing availability of sequence information provided the basis for the design of microarrays as valuable tool for functional genomics. The Institute for Genomic Research (TIGR) developed a $10-\mathrm{K}$ cDNA array which was employed, e.g. Campbell et al. (2008) used it to study transcriptional changes during naturally and chemically (BE) induced cessation of dormancy, where both resulted in similar alterations. Overall, the authors found a greater number of downregulated genes compared to dormant versus non-dormant tuber meristems. Among them were transcripts coding for storage proteins, such as patatin, for all major groups of protease inhibitors as well as ABA-inducible genes encoding members of the BURP motif containing RD22 family. Their data are indicative for a shift from storage to growth and for a declined ABA content (Campbell et al. 2008). In contrast, transcripts involved in cell division and growth, e.g. like such coding for histone proteins, cyclophilins and oxoglutarate-dependent dioxygenases, increased in their expression.

Since the TIGR 10-K array only represents part of the potato transcriptome, in 2008, a 44-K array was designed in collaboration between the Potato Oligo Chip Initiative (POCI) and Agilent Technologies (Kloosterman et al. 2008). Here, a set of approximately 250,000 EST sequences were assembled into 46,345 unigenes. Subsequently, specific 60-mer oligonucleotides were designed which is the foundation of the 44-K array allowing to study potato gene expression at a much broader level (Kloosterman et al. 2008). This microarray was, for example, used to study transcriptional changes following 3 days of $\mathrm{GA}_{3}$ treatment of wild type and AtCKX1 overexpressing tuber buds, respectively (Hartmann et al. 2011). At this time point, approx. $30 \%$ of wild-type tuber buds had started sprouting, while AtCKXI tubers did not. The data analysis revealed that in wild-type tuber buds, expression of most cell cycle-related genes was increased which was accompanied by increased expression of genes involved in replication and protein biosynthesis. In addition, expression of transcripts coding for components of the cytoskeleton, cell wall and such which are involved in cell wall modification was found to be exclusively stimulated in wild type, consistent with an increased cell division and proliferation rate during resumption of growth. Further differences between the two genotypes could be assigned to auxin and ethylene signalling events which contributed to the model shown in Fig. 3.

Together, an improved picture of molecular events associated with tuber bud break and sprouting has emerged; however, the order of events is still far from being understood and the key players are not known so far. In 2011, a high-quality genome sequence of a double-haploid potato clone has been published (The Potato Genome Sequencing Consortium 2011) which is an important resource for breeding programs, functional genomics and gene annotation. This together with full genome microarrays and detailed anatomical studies will help in further elucidating the molecular mechanisms underlying bud break and initiation of tuber sprouting.

Acknowledgments Work in our laboratory was supported by grants from BMBF (GABI, Biosicherheit), EU (EU-SOL project no. FOOD-CT-2006-016214) and FNR (HotPot). We wish to thank our co-workers D. Hofius, M. Senning, A. Hartmann, S. Ferreira, C. Prasch and S. Reid for their excellent work during the last years. We are grateful to N. Sauer for providing the AtSuc2::GFP construct as well as to M. Melzer and B. Claus for help with confocal microscopy.

\section{References}

Abelenda JA, Navarro C, Prat S (2011) From the model to the crop: genes controlling tuber formation in potato. Curr Opin Biotechnol 22:287-292

Agrimonti C, Visioli G, Marmiroli N (2000) In vitro and in silico analysis of two genes (A2-1 and G1-1) differentially regulated during dormancy and sprouting in potato tubers. Potato Res 43:325-333

Alexopoulos AA, Aivalakis G, Akoumianakis KA, Passam HC (2009) Bromoethane induces dormancy breakage and metabolic changes in tubers derived from true potato seed. Postharvest Biol Technol 54:165-171

Appeldoorn NJG, De Bruijn SM, Koot-Gronsveld EAM, Visser RGF, Vreugdenhil D, Van der Plas LHW (1999) Developmental changes in enzymes involved in the conversion of hexose phosphate and its subsequent metabolites during early tuberization of potato. Plant Cell Environ 22:1085-1096

Bachem C, Van Der Hoeven R, Lucker J, Oomen R, Casarini E, Jacobsen E, Visser R (2000) Functional genomic analysis of potato tuber life-cycle. Potato Res 43:297-312

Baena-Gonzalez E (2010) Energy signaling in the regulation of gene expression during stress. Mol Plant 3:300-313

Bialek K, Bielinska-Czarnecka M (1975) Gibberellin-like substances in potato tubers during their growth and dormancy. Bulletin de L'Académie Polonaise des Science, Série des sciences biologiques 23:213-218

Biemelt S, Hajirezaei M, Hentschel E, Sonnewald U (2000) Comparative analysis of abscisic acid content and starch degradation during storage of tubers harvested from different potato varieties. Potato Res 43:371-382

Bodlaender KBA, Lugt C, Marinus J (1964) The induction of secondgrowth in potato tubers. Europ Potato J 7:57-71

Börnke F, Sonnewald U, Biemelt S (2007) Potato. In: Pua EC, Davey MR (eds) Biotechnology in agriculture and forestry. Springer, Heidelberg, pp 297-315 
Brian PW, Hemming HG, Radley M (1955) A physiological comparison of gibberellic acid with some auxins. Physiol Plant 8:899-912

Burton WG (1989) The potato, 3rd edn. Longman Scientific and Technical, Essex

Campbell MA, Suttle JC, Sell TW (1996) Changes in cell cycle status and expression of p34 (cdc2) kinase during potato tuber meristem dormancy. Physiol Plant 98:743-752

Campbell M, Segear E, Beers L, Knauber D, Suttle J (2008) Dormancy in potato tuber meristems: chemically induced cessation in dormancy matches the natural process based on transcript profiles. Funct Integr Genomics 8:317-328

Campbell MA, Gleichsner A, Alsbury R, Horvath D, Suttle J (2010) The sprout inhibitors chlorpropham and 1,4-dimethylnaphthalene elicit different transcriptional profiles and do not suppress growth through a prolongation of the dormant state. Plant Mol Biol 73:181-189

Carraro N, Peaucelle A, Laufs P, Traas J (2006) Cell differentiation and organ initiation at the shoot apical meristem. Plant Mol Biol 60:811-826

Carrera E, Bou J, Garcia-Martinez JL, Prat S (2000) Changes in GA 20-oxidase gene expression strongly affect stem length, tuber induction and tuber yield of potato plants. Plant J 22:247-256

Claassens MMJ, Vreugdenhil D (2000) Is dormancy breaking of potato tubers the reverse of tuber initiation? Potato Res 43:347-369

Coleman WK (1983) An evaluation of bromoethane for breaking tuber dormancy in Solanum tuberosum L. Am Potato J 60:161-167

Coleman WK (1987) Dormancy release in potato tubers: a review. Am J Potato Res 64:57-68

Crookshanks M, Emmersen J, Welinder KG, Nielsen KL (2001) The potato tuber transcriptome: analysis of 6077 expressed sequence tags. FEBS Lett 506:123-126

Davies HV, Ross HA (1984) The pattern of starch and protein degradation in tubers. Potato Res 27:373-381

Davies HV, Ross HA (1987) Hydrolytic and phosphorolytic enzyme activity and reserve mobilization in sprouting tubers of potato (Solanum tuberosum L.). J Plant Physiol 126:387-396

Debast S, Nunes-Nesi A, Hajirezaei MR, Hofmann J, Sonnewald U, Fernie AR, Börnke F (2011) Altering trehalose-6-phosphate content in transgenic potato tubers affects tuber growth and alters responsiveness to hormones during sprouting. Plant Physiol 156:1754-1771

Destefano-Beltran L, Knauber D, Huckle L, Suttle J (2006a) Chemically forced dormancy termination mimics natural dormancy progression in potato tuber meristems by reducing ABA content and modifying expression of genes involved in regulating $\mathrm{ABA}$ synthesis and metabolism. J Exp Bot 57:2879-2886

Destefano-Beltran L, Knauber D, Huckle L, Suttle JC (2006b) Effects of postharvest storage and dormancy status on ABA content, metabolism, and expression of genes involved in ABA biosynthesis and metabolism in potato tuber tissues. Plant Mol Biol 61:687-697

Dettmer J, Elo A, Helariutta Y (2009) Hormone interactions during vascular development. Plant Mol Biol 69:347-360

Emilsson B (1949) Studies on the rest period and dormant period in the potato tuber. Acta Agricul Suec 3:189-284

Eshel D, Orenstein J, Tsror L, Hazanovsky M (2009) Environmentally friendly method for the control of sprouting and tuberborne diseases in stored potato. Acta Hort (ISHS) 830:363-368

Faivre-Rampant O, Cardle L, Marshall D, Viola R, Taylor MA (2004) Changes in gene expression during meristem activation processes in Solanum tuberosum with a focus on the regulation of an auxin response factor gene. J Exp Bot 55:613-622

Farre EM, Bachmann A, Willmitzer L, Trethewey RN (2001) Acceleration of potato tuber sprouting by the expression of a bacterial pyrophosphatase. Nat Biotechnol 19:268-272
Fernie AR, Willmitzer L (2001) Molecular and biochemical triggers of potato tuber development. Plant Physiol 127:1459-1465

Ferreira SJ, Senning M, Sonnewald S, Kessling PM, Goldstein R, Sonnewald U (2010) Comparative transcriptome analysis coupled to X-ray CT reveals sucrose supply and growth velocity as major determinants of potato tuber starch biosynthesis. BMC Genomics 1:93

Gong L, Yang YJ, Zhou J (2012) Genes involved in the synthesis and signaling pathway of strigolactone, a shoot branching inhibitor. Biol Plant 56:210-214

Gonzalez-Schain ND, Diaz-Mendoza M, Zurczak M, Suarez-Lopez P (2012) Potato constans is involved in photoperiodic tuberization in a graft-transmissible manner. Plant J 70:678-690

Hajirezaei M, Sonnewald U (1999) Inhibition of potato tuber sprouting: low levels of cytosolic pyrophosphate lead to non-sprouting tubers harvested from transgenic potato plants. Potato Res 42:353-372

Hajirezaei MR, Bornke F, Peisker M, Takahata Y, Lerchl J, Kirakosyan A, Sonnewald U (2003) Decreased sucrose content triggers starch breakdown and respiration in stored potato tubers (Solanum tuberosum). J Exp Bot 54:477-488

Halford NG, Hey S, Jhurreea D, Laurie S, McKibbin RS, Zhang Y, Paul MJ (2003) Dissection and manipulation of metabolic signalling pathways. Annals Appl Biol 142:25-31

Hannapel DJ (2010) A model system of development regulated by the long-distance transport of mRNA. J Integr Plant Biol 52:40-52

Hartmann A, Senning M, Hedden P, Sonnewald U, Sonnewald S (2011) Reactivation of meristem activity and sprout growth in potato tubers require both cytokinin and gibberellin. Plant Physiol 155:776-796

Hedden P (2001) Gibberellin metabolism and its regulation. J Plant Growth Regul 20:317-318

Hemberg T (1949) Significance of growth-inhibiting substances and auxin for the rest period of potato tuber. Physiol Plant 2:24-36

Hemberg T (1970) The action of some cytokinins on the rest-period and the content of acid growth-inhibiting substances in potato. Physiol Plant 23:850-858

Hemberg T (1985) Potato rest. In: Li PH (ed) Potato physiology. Academic Press, New York, pp 353-388

Imlau A, Truernit E, Sauer N (1999) Cell-to-cell and long-distance trafficking of the green fluorescent protein in the phloem and symplastic unloading of the protein into sink tissues. Plant Cell 11:309-322

Jackson SD (1999) Multiple signaling pathways control tuber induction in potato. Plant Physiol 119:1-8

Kloosterman B, Vorst O, Hall RD, Visser RGF, Bachem CW (2005) Tuber on a chip: differential gene expression during potato tuber development. Plant Biotechnol J 3:505-519

Kloosterman B, Navarro C, Bijsterbosch G, Lange T, Prat S, Visser RG, Bachem CW (2007) StGA2ox1 is induced prior to stolon swelling and controls GA levels during potato tuber development. Plant J 52:362-373

Kloosterman B, De Koeyer D, Griffiths R, Flinn B, Steuernagel B, Scholz U, Sonnewald S, Sonnewald U, Bryan GJ, Prat S, Banfalvi Z, Hammond JP, Geigenberger P, Nielsen KL, Visser RG, Bachem CW (2008) Genes driving potato tuber initiation and growth: identification based on transcriptional changes using the POCI array. Funct Integr Genomics 8:329-340

Kloosterman B, Abelenda JA, Gomez Mdel M, Oortwijn M, de Boer JM, Kowitwanich K, Horvath BM, van Eck HJ, Smaczniak C, Prat S, Visser RG, Bachem CW (2013) Naturally occurring allele diversity allows potato cultivation in northern latitudes. Nature 495:246-250

Korableva N, Karaveava KA, Metlitskii LV (1980) Changes of abscisic acid content in potato tuber tissues in the period of deep dormancy and during germination. Fiz Rast 27:585-591 
Lang GA, Early JD, Martin GC, Darnell RL (1987) Endo-, para- and eco-dormancy: physiological terminology and classification for dormancy research. Hort Sci 22:371-377

Law RD, Suttle JC (2003) Transient decreases in methylation at 5'CCGG- $3^{\prime}$ sequences in potato (Solanum tuberosum L.) meristem DNA during progression of tubers through dormancy precede the resumption of sprout growth. Plant Mol Biol 51:437-447

Law D, Suttle JC (2004) Changes in histone H3 and H4 multi-acetylation during natural and forced dormancy break in potato tubers. Physiol Plant 120:642-649

Levy D, Veilleux RE (2007) Adaption of potato to high temperatures and salinity-a review. Am J Potato Res 84:487-506

Liu BL, Zhang N, Wen YK, Si HJ, Wang D (2012) Identification of differentially expressed genes in potato associated with tuber dormancy release. Mol Biol Rep 39:1277-11287

Lunn JE, Feil R, Hendriks JH, Gibon Y, Morcuende R, Osuna D, Scheible WR, Carillo P, Hajirezaei MR, Stitt M (2006) Sugarinduced increases in trehalose 6-phosphate are correlated with redox activation of ADP-glucose pyrophosphorylase and higher rates of starch synthesis in Arabidopsis thaliana. Biochem $\mathbf{J}$ 397:139-148

Macdonald MM, Osborne DJ (1988) Synthesis of nucleic acids and protein in tuber buds of Solanum tuberosum during dormancy and early sprouting. Physiol Plant 73:392-400

Marmiroli N, Agrimonti C, Visioli G, Colauzzi M, Guarda G, Zuppini A (2000) Silencing of G1-1 and A2-1 genes: effects on general plant phenotype and on tuber dormancy in Solanum tuberosum L. Potato Res 43:313-323

Meigh DF (1969) Suppression of sprouting in stored potatoes by volatile organic compounds. J Sci Food Agric 20:159-164

Morris WL, Ducreux LJM, Hedden P, Millam S, Taylor MA (2006) Overexpression of a bacterial 1-deoxy-D-xylulose 5-phosphate synthase gene in potato tubers perturbs the isoprenoid metabolic network: implications for the control of the tuber life cycle. J Exp Bot 57:3007-3018

Navarro C, Abelenda JA, Cruz-Oro E, Cuellar CA, Tamaki S, Silva J, Shimamoto K, Prat S (2011) Control of flowering and storage organ formation in potato by FLOWERING LOCUS T. Nature 478:119-122

OECD consensus document (2002) http://www.oecd.org/science/ biotrack/46815167.pdf

Oparka KJ, Roberts AG, Boevink P, Santa Cruz S, Roberts L, Pradel KS, Imlau A, Kotlizky G, Sauer N, Epel B (1999) Simple, but not branched, plasmodesmata allow the nonspecific trafficking of proteins in developing tobacco leaves. Cell 97:743-754

Pasare SA, Ducreux LJ, Morris WL, Campbell R, Sharma SK, Roumeliotis E, Kohlen W, van der Krol S, Bramley PM, Roberts AG, Fraser PD, Taylor MA (2013) The role of the potato (Solanum tuberosum) CCD8 gene in stolon and tuber development. New Phytol 198:1108-1120

Paul M (2007) Trehalose 6-phosphate. Curr Opin Plant Biol 10:303-309

Prange RK, Kalt W, Daniels-Lake BJ, Liew CL, Page RT, Walsh JR, Dean P, Coffin R (1998) Using ethylene as a sprout control agent in stored 'Russet Burbank' potatoes. J Am Soc Hort Sci 123:463-469

Rappaport L (1956) Growth regulating metabolites: gibberellin compounds derived from rice disease-producing fungus exhibit powerful plant growth regulating properties. Calif Agric 10:4-11

Rappaport L, Lippert L, Timm H (1957) Sprouting, plant growth, and tuber production as affected by chemical treatment of white potato seed pieces. Am J Potato Res 34:254-260

Rentzsch S, Podzimska D, Voegele A, Imbeck M, Muller K, Linkies A, Leubner-Metzger G (2012) Dose- and tissue-specific interaction of monoterpenes with the gibberellin-mediated release of potato tuber bud dormancy, sprout growth and induction of alpha-amylases and beta-amylases. Planta 235:137-151

Rinne PL, Kaikuranta PM, van der Schoot C (2001) The shoot apical meristem restores its symplasmic organization during chillinginduced release from dormancy. Plant J 26:249-264

Rinne PL, Welling A, Vahala J, Ripel L, Ruonala R, Kangasjarvi J, van der Schoot C (2011) Chilling of dormant buds hyperinduces Flowering Locus $\mathrm{T}$ and recruits GA-inducible 1,3-betaglucanases to reopen signal conduits and release dormancy in Populus. Plant Cell 23:130-146

Ronning CM, Stegalkina SS, Ascenzi RA, Bougri O, Hart AL, Utterbach TR, Vanaken SE, Riedmuller SB, White JA, Cho J, Pertea GM, Lee Y, Karamycheva S, Sultana R, Tsai J, Quackenbush J, Griffiths HM, Restrepo S, Smart CD, Fry WE, Van Der Hoeven R, Tanksley S, Zhang P, Jin H, Yamamoto ML, Baker BJ, Buell CR (2003) Comparative analyses of potato expressed sequence tag libraries. Plant Physiol 131:419-429

Roumeliotis E, Kloosterman B, Oortwijn M, Kohlen W, Bouwmeester HJ, Visser RG, Bachem CW (2012) The effects of auxin and strigolactones on tuber initiation and stolon architecture in potato. J Exp Bot 63:4539-4547

Ruyter-Spira C, Al-Babili S, van der Krol S, Bouwmeester H (2013) The biology of strigolactones. Trends Plant Sci 18:72-83

Rylski I, Rappapor L, Pratt HK (1974) Dual effects of ethylene on potato dormancy and sprout growth. Plant Physiol 53:658-662

Scarpella E, Barkoulas M, Tsiantis M (2010) Control of leaf and vein development by auxin. Cold Spring Harb Perspect Biol 2:a001511. doi:10.1101/cshperspect.a001511

Senning M, Sonnewald U, Sonnewald S (2010) Deoxyuridine triphosphatase expression defines the transition from dormant to sprouting potato tuber buds. Mol Breed 26:525-531

Smith OE, Rappaport L (1961) Endogenous gibberellins in resting and sprouting potato tubers. Adv Chem Ser 28:42-48

Sonnewald U (2001) Control of potato tuber sprouting. Trends Plant Sci 6:333-335

Sorce C, Lorenzi R, Ceccarelli N, Ranalli P (2000) Changes in free and conjugated IAA during dormancy and sprouting of potato tubers. Austral J Plant Physiol 27:371-377

Sorce C, Lombardi L, Giorgetti L, Parisi B, Ranalli P, Lorenzi R (2009) Indoleacetic acid concentration and metabolism changes during bud development in tubers of two potato (Solanum tuberosum) cultivars. J Plant Physiol 166:1023-1033

Sukhova L, MachÁČkovÁ I, Eder J, Bibik N, Korableva N (1993) Changes in the levels of free IAA and cytokinins in potato tubers during dormancy and sprouting. Biol Plant 35:387-391

Suttle JC (1998a) Involvement of ethylene in potato microtuber dormancy. Plant Physiol 118:843-848

Suttle JC (1998b) Postharvest changes in endogenous cytokinins and cytokinin efficacy in potato tubers in relation to bud endodormancy. Physiol Plant 103:59-69

Suttle J (2001) Dormancy-related changes in cytokinin efficacy and metabolism in potato tubers during postharvest storage. Plant Growth Regul 35:199-206

Suttle JC (2004a) Involvement of endogenous gibberellins in potato tuber dormancy and early sprout growth: a critical assessment. J Plant Physiol 161:157-164

Suttle JC (2004b) Physiological regulation of potato tuber dormancy. Amer J Plant Physiol 81:253-262

Suttle J (2007) Dormancy and sprouting. Advances and perspectives. Elsevier BV, Vreugdenhil D (ed) Potato biology and biotechnology, pp 287-309

Suttle J (2008) Effects of synthetic phenylurea and nitroguanidine cytokinins on dormancy break and sprout growth in Russet Burbank minitubers. Am J Potato Res 85:121-128 
Suttle J (2009) Ethylene is not involved in hormone- and bromoethane-induced dormancy break in Russet Burbank minitubers. Am J Potato Res 86:278-285

Suttle JC, Hultstrand J (1994) Role of endopgenous abscisic acid in potato microtuber dormancy. Plant Physiol 105:891-896

Suttle JC, Abrams SR, De Stefano-Beltran L, Huckle LL (2012) Chemical inhibition of potato ABA- 8 -hydroxylase activity alters in vitro and in vivo ABA metabolism and endogenous ABA levels but does not affect potato microtuber dormancy duration. J Exp Bot 63:5717-5725

Teper-Bamnolker P, Dudai N, Fischer R, Belausov E, Zemach H, Shoseyov O, Eshel D (2010) Mint essential oil can induce or inhibit potato sprouting by differential alteration of apical meristem. Planta 232:179-186

Teper-Bamnolker P, Buskila Y, Lopesco Y, Ben-Dor S, Saad I, Holdengreber V, Belausov E, Zemach H, Ori N, Lers A, Eshel D (2012) Release of apical dominance in potato tuber is accompanied by programmed cell death in the apical bud meristem. Plant Physiol 158:2053-2067

The Potato Genome Sequencing Consortium (2011) Genome sequence and analysis of the tuber crop potato. Nature 475:189-195

Turnbull CGN, Hanke DE (1985a) The control of bud dormancy in potato tubers: evidence for the primary role of cytokinins and a seasonal pattern of changing sensitivity to cytokinin. Planta 165:359-365

Turnbull CGN, Hanke DE (1985b) The control of bud dormancy in potato tubers: evidence for the primary role of cytokinins and a seasonal pattern of changing sensitivity to cytokinin. Planta 165:359-365

Vaughn K, Lehnen G (1991) Mitotic disrupter herbicides. Weed Sci 39:450-457

Viola R, Pelloux J, van der Ploeg A, Gillespie T, Marquis N, Roberts AG, Hancock RD (2007) Symplastic connection is required for bud outgrowth following dormancy in potato (Solanum tuberosum L.) tubers. Plant Cell Environ 30:973-983

Visser RGF, Vreugdenhil D, Hendriks T, Jacobsen E (1994) Gene expression and carbohydrate content during tuber to stolon transition in potatoes (Solanum tuberosum). Physiol Plant 75:525-531

Wiltshire JJJ, Cobb AH (1996) A review of the physiology of potato tuber dormancy. Annals Appl Biol 129:553-569

Xu X, Vreugdenhil D, van Lammeren AAM (1998) Cell division and cell enlargement during potato tuber formation. J Exp Bot 49:573-582 